\title{
Investigation of Diospyros Kaki L.f husk extracts as corrosion inhibitors and bactericide in oil field
}

\author{
Jie Zhang ${ }^{1}$, Yingpan Song ${ }^{1}$, Huijun Su' ${ }^{1}$ Li Zhang ${ }^{1}$, Gang Chen $^{1 *}$ and Jingrui Zhao ${ }^{2}$
}

\begin{abstract}
Background: Hydrochloric acid is used in oil-well acidizing commonly for improving the crude oil production of the low-permeable reservoirs, while it is a great challenge for the metal instruments involved in the acidification. Developing natural products as oilfield chemicals is a straight way to find less expensive, green and eco-friendly materials. The great plant resources in Qin-ling and Ba-shan Mountain Area of Shannxi Province enable the investigating of new green oil field chemicals. Diospyros Kaki L.f (persimmon), a famous fruit tree is widely planted in Qin-ling and Ba-shan Mountain Area of Shaanxi Province. It has been found that the crude persimmon extracts are complex mixtures containing vitamins, $p$-coumaric acid, gallic acid, catechin, flavonoids, carotenoids and condensed tannin and so on, which indicates the extracts of persimmon husk suitable to be used as green and eco-friendly corrosion inhibitors.

Findings: Extracts of persimmon husk were investigated, by using weight loss and potentiodynamic polarisation techniques, as green and eco-friendly corrosion inhibitors of Q235A steel in $1 \mathrm{M} \mathrm{HCl}$. The inhibition efficiency of the extracts varied with extract concentration from 10 to $1,000 \mathrm{mg} / \mathrm{L}$. There are some synergistic effects between the extracts and Kl, KSCN and HMTA. Potentiodynamic polarization studies indicate that extracts are mixed-type inhibitors. Besides, the extracts were screened for antibacterial activity against oil field microorganisms, and they showed good to moderate activity against SRB, IB and TGB.

Conclusions: The inhibition efficiency of the extracts varied with extract concentration from 10 to $1,000 \mathrm{mg} / \mathrm{L}$, and the highest reaches to $65.1 \%$ with the con concentration of 1,000 mg/L WE. Kl, KSCN and HMTA they can enhance the IE of WE effectively to $97.3 \%$ at most, but not effective for KI and KSCN to AE. Tafel polarisation measurements indicate the extracts behave as mixed type inhibitor. Investigation of the antibacterial activity against oil field microorganism showed the extracts can inhibit SRB, IB and TGB with moderate to highly efficiency under 1,000 mg/L, which makes extracts potential to be used as bifunctional oil field chemicals.
\end{abstract}

Keywords: Persimmon, Acid corrosion, Weight loss, Microbiological corrosion

\section{Introduction}

Hydrochloric acid is used in oil-well acidizing commonly for improving the crude oil production of the lowpermeable reservoirs [1], while it is a great challenge for the metal instruments involved in the acidification, as shown in Figure 1. Due to the aggressive nature of $\mathrm{HCl}$ and other corrosive factors, the practice of inhibiters is commonly used to reduce such corrosive attack [2]. Compounds, containing functional electronegative groups and abundant p-electron in conjugated double or triple

\footnotetext{
* Correspondence: gangchen@xsyu.edu.cn

${ }^{1}$ College of Chemistry and Chemical Engineering, Xi'an Shiyou University,

Xi'an Shaanxi 710065, People's Republic of China

Full list of author information is available at the end of the article
}

bonds, are found to be very efficient as corrosion inhibitors [3]. It has been commonly recognized that an organic inhibitor usually promotes the formation of a chelate film on a metal surface by transferring electrons from the organic compounds to the metal and forming a coordinate covalent bond during the chemical adsorption, thereby resisting the corrosion in acidic solutions [4]. In present, the heteroatomic organic compounds as well as aromatic compounds are the widely used efficient corrosion inhibitors.

The great plant resources in Qin-ling and Ba-shan Mountain Area of Shannxi Province enable the investigating of new green oil field chemicals. Diospyros Kaki L.f (persimmon), a famous fruit tree is widely planted in

\section{() Chemistry Central}



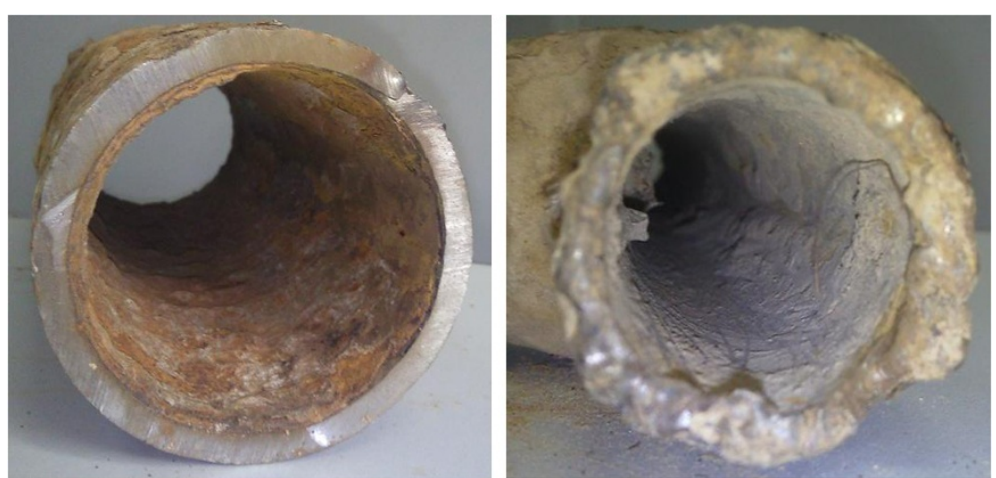

Figure 1 The corrosion in the re-injection pipes of the oil field.

Qin-ling and Ba-shan Mountain Area of Shaanxi Province. It has been found that the crude persimmon extracts are complex mixtures containing vitamins, $p$-coumaric acid, gallic acid, catechin, flavonoids, carotenoids and condensed tannin and so on [5], which indicates the extracts of persimmon husk suitable to be used as green and ecofriendly corrosion inhibitors. Moreover, microbiologically influenced corrosion (MIC) caused by oil field microorganisms, such as sulfate reducing bacteria (SRB), iron bacteria (IB), and total general bacteria (TGB), is also a considerable problem. As it has been reported that the compounds combine with proteins and show some antibacterial activities [6], the persimmon extracts are anticipated to be corrosion inhibitors and bactericides for oil field microorganisms in oil field water treatment, as shown in Figure 2.

The present work focuses on the assessment of persimmon extracts as corrosion inhibitors for Q235A steel in $\mathrm{HCl}$ solution. The corrosion protection effect and the mechanism of corrosion inhibition were investigated by means of linear DC polarization. The bioactivity against oil field microorganisms was also screened for the inhibition of MIC.

\section{Experimental}

\section{Materials and methods}

Persimmon husk, gathered in October 2011 in Qinling Mount, were washed by clean water and dried at $60^{\circ} \mathrm{C}$. Then it was shattered into powders, and the powders were heated under reflux with water or alcohol for $4 \mathrm{~h}$. The mixture was cool to the room temperature, and yellow solution was filtered, and solvent was removed to yield dry extract. The persimmon husk extracts obtained by use of water and alcohol were named as $\mathrm{WE}$ and $\mathrm{AE}$ respectively.

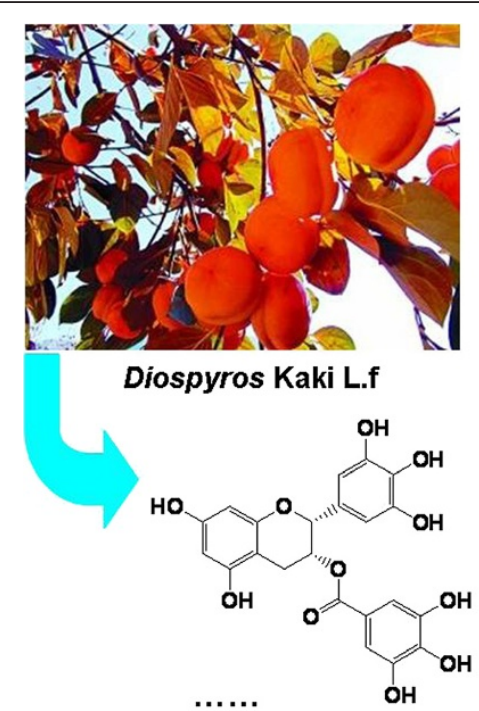

Figure 2 Development of persimmon extract as oil field chemical.
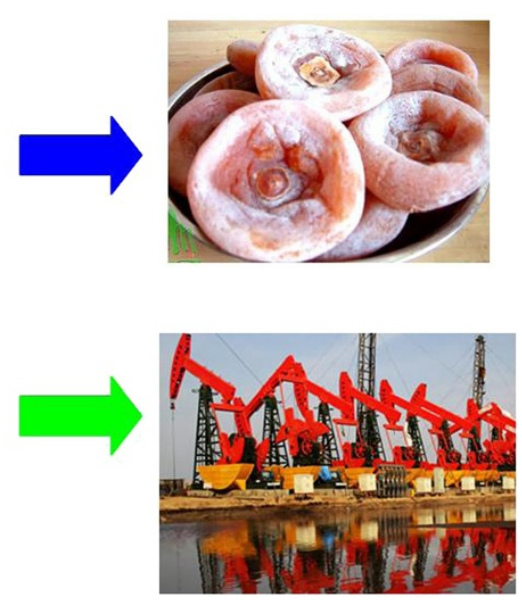

Oil-field Water Treatment 


\section{Gravimetric measurements}

The corrosion tests were performed on Q235A with a composition (in wt.\%) C: 0.22, P: 0.045, Si: 0.35, S: 0.05, Mn: 1.40, and Fe balance. The electrolyte solution was $1 \mathrm{M} \mathrm{HCl}$, prepared from analytical grade $38 \% \mathrm{HCl}$ and distilled water. The concentrations of persimmon leaves extracts were employed as 10, 50, 100, 200, 500, and $1,000 \mathrm{mg} / \mathrm{L}$. All tests have been performed in water solutions and at $60 \pm 0.5^{\circ} \mathrm{C}$ for $5 \mathrm{~h}$. The gravimetric tests were carried out according to the Standard of Petroleum and Natural Gas Industry of People's Republic of China (Method of SY/T5273-2000, Evaluation method for behavior of corrosion inhibitor for produced water of oilfield) with a few modifications. Each test was done with three specimens simultaneously to give reproducible results.

\section{Electrochemical measurements}

The electrodes were mechanically abraded with a series of emery papers (800 and 1,200 grades), then rinsed in acetone and double-distilled water before their immersion in the experimental solution. Electrochemical measurements were conducted in a conventional threeelectrode thermostated cell. The electrode was inserted into a Teflon tube and isolated with polyester so that only its section $\left(0.5 \mathrm{~cm}^{2}\right)$ was allowed to contact the aggressive solutions. A platinum disk as counter electrode and standard calomel electrode (SCE) as the reference electrode have been used in the electrochemical studies.

The potentiodynamic curves were recorded using a CS350 system connected to a personal computer. The working electrode was first immersed in the test solution for $60 \mathrm{~min}$ to establish a steady state open circuit potential. After measuring the open circuit, potential dynamic polarization curves were obtained with a scan rate of $0.5 \mathrm{mV} / \mathrm{s}$. Corrosion rates (corrosion current densities) were obtained from the polarization curves by linear extrapolation of the anodic and cathodic branches of the Tafel plots at points $100 \mathrm{mV}$ more positive and more negative than the $\mathrm{E}_{\mathrm{corr}}$.

CS350 electrochemical workstation hardware parameters:

Potentiostat potential control: $\pm 10 \mathrm{~V}$; Current Control Range: $\pm 2.0 \mathrm{~A}$; Potential control precision: $0.1 \% \times$ full scale reading $\pm 1 \mathrm{mV}$; Current control accuracy: $0.1 \% \times$ full scale reading; Potential resolution: $10 \mu \mathrm{V}(>100 \mathrm{~Hz})$, $2 \mu \mathrm{V}(<10 \mathrm{~Hz})$; Current resolution: <10 pA; Potential rise time: $<1 \mu \mathrm{S}(<10 \mathrm{~mA}),<10 \mu \mathrm{S}(<2 \mathrm{~A})$; Auxiliary 24bit data acquisition-10 KHz, 20bit-1 KHz; Reference electrode input impedance: 1012 ohms || 20 pF; Current range 2A-00 nA, a total of 8 files; Tank pressure: $21 \mathrm{~V}$; $\mathrm{CV}$ and LSV scan rate: $0.01-20000 \mathrm{mV} / \mathrm{s}$; CA and CC pulse width: $0.0001-1000 \mathrm{~s}$; Potential scan potential incremental: $0.1 \mathrm{mV}-1 \mathrm{~V} / \mathrm{mS}$; SWV frequency: 0.001$100 \mathrm{KHz}$; DPV and NPV pulse width: 0.0001-1000 s; AD data acquisition: 16 bits-1 MHz, 24bit-100Hz; Minimum potential increment CV: $0.075 \mathrm{mV}$.

\section{Microbiological monitoring}

Viable counts of SRB, TGB and FB were determined according to the Standard of Petroleum and Natural Gas Industry of People's Republic of China (Method of SY/T 5890-1993, The national method of the bactericidal agent's performance). The produced water containing the three kinds of bacteria was gathered from Zichang Oilfield Factory, Yanchang Oilfield.

\section{Findings}

Inhibitor properties and mechanism

Developing natural products as oilfield chemicals is a straight way to find less expensive, green and ecofriendly materials. Based on the fruitful and large quantity of local plant resources of Shannxi Province, several plants have been investigated in our work for the application in oilfield chemistry. The inhibition efficiency (IE) of extracts of persimmon husk were investigated in the concentration range 10 to $1,000 \mathrm{mg} / \mathrm{L}$ in $1 \mathrm{M} \mathrm{HCl}$, and the changes of IE (\%) with the inhibitor concentration are summarized in Table 1. From the table, it is apparent that the extracts inhibit the corrosion with different efficiency under different concentrations, the IE increases with increasing extract concentration, and the highest reaches to $65.1 \%$.

Increasing in IE with increasing additive concentration can be explained on the basis of additive adsorption. The presence of $\mathrm{N}, \mathrm{O}, \mathrm{S}$ atoms and conjugated double bonds in the organic compounds makes the formation of $\mathrm{p}-\mathrm{d}$ bonds from overlap of $\mathrm{p}$ electrons with the

Table 1 The inhibition efficiency of WE and AE measured by weight loss

\begin{tabular}{cccc}
\hline Extract & $\begin{array}{c}\text { Concentration } \\
(\mathbf{m g} / \mathbf{L})\end{array}$ & $\begin{array}{c}\text { Corrosion rate } \\
\left(\mathbf{g} / \mathbf{m}^{\mathbf{2}} \cdot \mathbf{h}\right)\end{array}$ & $\begin{array}{c}\text { Inhibition efficiency } \\
\mathbf{( \% )}\end{array}$ \\
\hline- & - & 90.6 & 0 \\
WE & 10 & 60.2 & 33.6 \\
WE & 50 & 41.9 & 53.7 \\
WE & 100 & 39.6 & 56.3 \\
WE & 200 & 38.7 & 57.2 \\
WE & 500 & 35.3 & 61.1 \\
WE & 1,000 & 31.6 & 65.1 \\
AE & 10 & 59.0 & 34.5 \\
AE & 50 & 52.3 & 42.0 \\
AE & 100 & 48.1 & 46.7 \\
AE & 200 & 44.6 & 50.5 \\
AE & 500 & 39.7 & 55.9 \\
AE & 1,000 & 38.1 & 57.7 \\
\hline
\end{tabular}


vacant $3 \mathrm{~d}$ orbital of iron atoms, which enhances the adsorption of the compounds on the metal surface [7]. The steady conformations of two phenol compounds in persimmon, epicatechin gallate and hydrolysable tannin, were shown in Figure 3. It is apparent that there are abundant oxygen atoms with couples of $\mathrm{p}$ electrons and several conjugated double bonds and aryl groups, which may afford different manner to coordinate with steel surface.

In addition, the phenol compounds are high reductive, and researches have demonstrated that persimmon extract affords protection against lipid peroxidation in ex vivo liver homogenates when the tannin of persimmon is added before incubation with $\mathrm{Fe}^{2+}$ /ascorbic acid or $\mathrm{H}_{2} \mathrm{O}_{2}$ [8], which indicate that the phenols can be oxidized to benzoquinone by the $\mathrm{O}_{2}$ dissolved in the solution, which can inhibit the oxygen-adsorption corrosion.

\section{Synergistic effect}

KI, KSCN and hexamethylenetetramine (HMTA) are used as synergistic additives in some corrosion inhibitor formulations effectively. In the following work, the effect of KI, KSCN and HMTA on the inhibitive performance of the extracts was studied using weight loss determinations. The IE values under the concentration of $100 \mathrm{mg} / \mathrm{L}$ of KI, KSCN and HMTA companied with $500 \mathrm{mg} / \mathrm{L}$ of extracts are presented in Table 2. Inspection of Table 3 reveals that KI, KSCN and HMTA they can enhance the IE of WE effectively to as high as $97.3 \%$. But the synergistic effect is not effective for KI, KSCN to AE, only HMTA is effective to give the IE of $90.5 \%$. The reason might lie on the fruitful p-electrons of $\mathrm{N}, \mathrm{O}$ and triple bond, which can form covalent bonds between the molecules and the ion surface, capture $\mathrm{H}^{+}$to release the acidity and even join the molecules as "bridges" to conform the protective film on the ion surface.

\section{Tafel polarisation measurements}

The anodic and cathodic polarization curves for a mild steel electrode in $1 \mathrm{M} \mathrm{HCl}$ in absence and presence of
Table 2 The corrosion rate inhibition efficiency of extracts companioning with $\mathrm{KI}, \mathrm{KSCN}$ and HMTA

\begin{tabular}{ccc}
\hline Formulation & $\begin{array}{c}\text { Corrosion rate } \\
\left(\mathbf{g} / \mathbf{m}^{\mathbf{2}} \cdot \mathbf{h}\right)\end{array}$ & $\begin{array}{c}\text { Inhibition efficiency } \\
\text { (\%) }\end{array}$ \\
\hline- & 90.6 & $/$ \\
$\mathrm{Kl}$ & 36.1 & 60.3 \\
$\mathrm{KSCN}$ & 40.7 & 55.3 \\
$\mathrm{HMTA}$ & 24.7 & 72.8 \\
$\mathrm{WE}+\mathrm{Kl}$ & 2.5 & 97.3 \\
WE + KSCN & 8.6 & 90.6 \\
WE + HMTA & 4.9 & 94.6 \\
$\mathrm{AE}+\mathrm{Kl}$ & 21.4 & 76.5 \\
$\mathrm{AE}+\mathrm{KSCN}$ & 45.1 & 50.4 \\
$\mathrm{AE}+\mathrm{HMTA}$ & 8.6 & 90.5 \\
\hline
\end{tabular}

different concentrations of $\mathrm{AE}$ at $298 \mathrm{~K}$ are shown in Figure 4. Table 3 shows the electrochemical corrosion kinetic parameters, i.e., corrosion potential $\left(E_{\mathrm{corr}}\right)$, cathodic and anodic Tafel slopes $(\beta \mathrm{a}, \beta \mathrm{c})$ and corrosion current density $I_{\text {corr }}$ obtained by extrapolation of the Tafel lines. The IE (\%) is also calculated from the following equation:

$$
E(\%)=\frac{I_{\text {corr }}-I_{\text {corr }}}{I_{\text {corr }}} \times 100
$$

where $I_{\text {corr }}$ and $I_{\text {corr(i) }}$ are corrosion current densities obtained in the absence and presence of inhibitors, respectively. As it was expected both anodic and cathodic reactions of mild steel electrode corrosion were inhibited by the increase of the AE. This result suggests that the addition of the WE reduces anodic dissolution and also retards the hydrogen evolution reaction [9]. It can be seen that the corrosion rate is decreased and inhibition efficiency IE is increased by increasing inhibitor concentration. With a concentration of $1,000 \mathrm{mg} / \mathrm{L}$, WE exhibits maximum IE of $79.6 \%$. The extract causes changes in the anodic, cathodic Tafel slopes and the Ecorr values
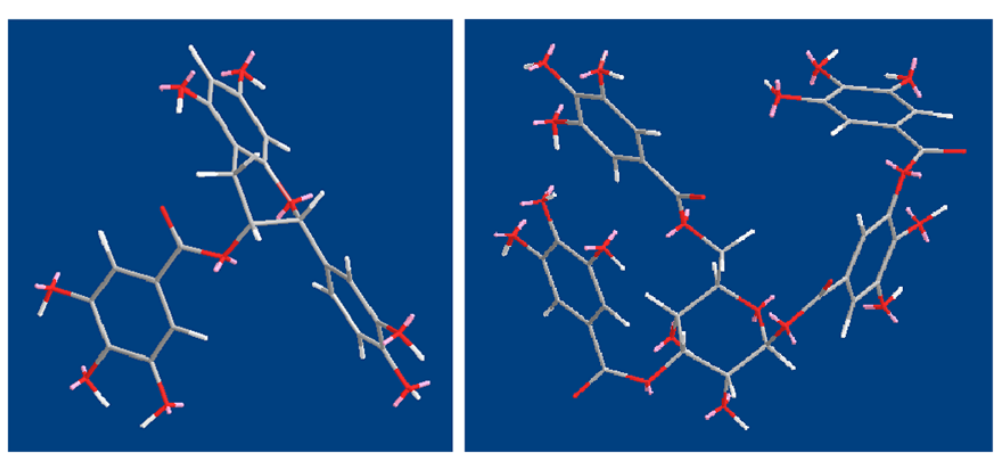

Figure 3 The steady conformation of epicatechin gallate and hydrolysable tannin. 
Table 3 Potentiodynamic polarization parameters for the corrosion of the Q230A steel in the $\mathrm{HCl}$ solution containing WE

\begin{tabular}{|c|c|c|c|c|c|c|}
\hline $\begin{array}{l}\text { Concentration } \\
(\mathrm{mg} / \mathrm{L})\end{array}$ & $\begin{array}{c}\text {-Ecorr } \\
(\mathrm{mV})\end{array}$ & $\begin{array}{c}\text { Icorr } \\
\left(\mu \mathrm{A} / \mathrm{cm}^{2}\right)\end{array}$ & $\begin{array}{c}\beta a \\
(\mathrm{mV} / \mathrm{dec})\end{array}$ & $\begin{array}{c}\beta c \\
(\mathrm{mV} / \mathrm{dec})\end{array}$ & $\begin{array}{c}\text { Corrosion rate } \\
(\mathrm{mm} / \mathrm{a})\end{array}$ & $\begin{array}{l}\text { IE } \\
(\%)\end{array}$ \\
\hline- & 0.46083 & 151.440 & 90.431 & 155.08 & 1.7753 & - \\
\hline 10 & 0.46344 & 89.193 & 77.592 & 142.57 & 1.0491 & 40.9 \\
\hline 50 & 0.46471 & 141.990 & 107.110 & 166.89 & 1.5727 & 11.4 \\
\hline 100 & 0.45503 & 90.507 & 77.031 & 146.09 & 1.0646 & 40.0 \\
\hline 200 & 0.45521 & 31.412 & 63.159 & 119.64 & 0.3695 & 79.2 \\
\hline 500 & 0.46082 & 51.929 & 62.717 & 81.32 & 0.6974 & 60.7 \\
\hline 1,000 & 0.45254 & 30.770 & 58.282 & 135.34 & 0.36192 & 79.6 \\
\hline
\end{tabular}

in the presence of different concentrations. $E_{\text {corr }} \beta \mathrm{a}$ and $\beta c$ values do not change appreciably with the addition of the inhibitor, which indicates that the inhibitor is not only interfering with the anodic dissolution or cathodic hydrogen evolution reactions independently but also acts as a mixed-type (anodic/cathodic) of inhibitor [10]. Increasing IE with increasing concentration of the $\mathrm{AE}$ shows that the inhibition actions are due to its adsorption on the steel surface [11]. The IEs obtained from potentiodynamic polarization were quite different from those calculated from weight-loss measurements, which is attributable to the fact that the weight-loss method gives average corrosion rate, whereas electrochemical method gives instantaneous corrosion rates. These differences may arise frequently because of the difference in the time required to form an adsorbed layer of inhibitors on metal surface [12].

\section{Antibacterial activity against oil field microorganism}

Produced water is a consequence of oil field exploitation by waterflood or steam injection or having an aquifer linked to the reservoir. The most usual disposal way for the high-volumed produced water is to re-inject it to the well after treatment, which will meet some requirements imposed by environmental and exploitation regulations, among which microbiologically influenced corrosion (MIC) is an example. MIC, mainly caused by the growth of such oil field microorganism as sulfate reducing bacteria $(\mathrm{SRB})$, iron bacteria (IB) and total general bacteria (TGB) in oil pipelines, is considered as a major problem

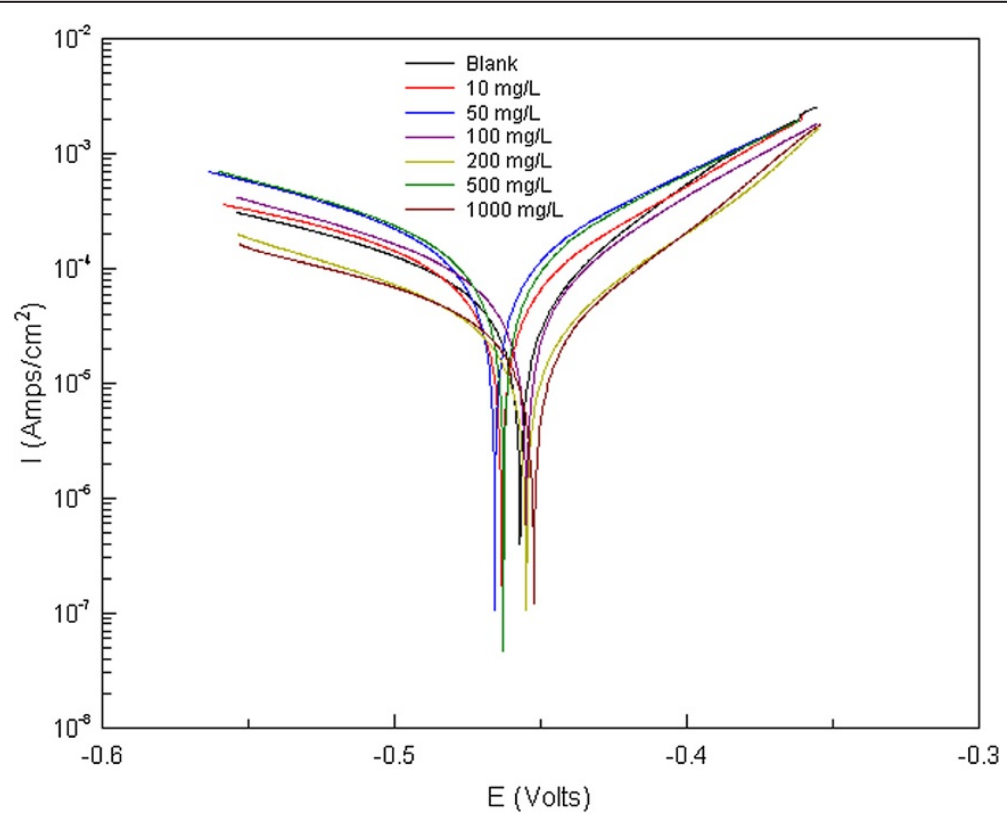

Figure 4 Typical polarization curves for corrosion of Q235A steel in $1 \mathrm{M} \mathrm{HCl}$ in the absence and presence of different concentrations of WE. 
Table 4 The antifungal activity of persimmon extracts against oil field MIC

\begin{tabular}{ccccc}
\hline Extract & Concentration & \multicolumn{3}{c}{ Microbiotic Concentration $\mathbf{m L}$} \\
\cline { 2 - 5 } & $\mathbf{m g} / \mathbf{L}$ & iSRB & IB & TGB \\
\hline- & - & 110.0 & 110.0 & 110.0 \\
WE & 500 & 110.0 & 110.0 & 70.0 \\
& 1,000 & 2.0 & 2.0 & 1.3 \\
\multirow{2}{*}{$\mathrm{AE}$} & 500 & 2.0 & 0.6 & 25.0 \\
& 1,000 & 0.9 & 0.0 & 6.0 \\
\hline
\end{tabular}

for water treatment in the oil field [13]. Based on this case, different treatment system to inhibit corrosion should be considered, among which using bactericide has received the greatest acceptance. Currently, oxidizer, aldehyde, quatemary ammonium salt and heterocycle compounds, such as $\mathrm{Cl}_{2}, \mathrm{ClO}_{2}$, formaldehyde, pentane- 1 ,5-dial, trichloroisocyanuric acid (TCCA) and ect., have been used as bactericides [14], but the toxicity and oxidation tests have been conducted on a limited selection.

Since tannins have been found to incline to combine with proteins and shown some antibacterial activities [6], the persimmon extracts are anticipated to be bactericides for oil field microorganism. In the following work, the antifungal activity of these extracts against oil field microorganism was tested under the concentrations of $1,000 \mathrm{mg} / \mathrm{L}$ and $500 \mathrm{mg} / \mathrm{L}$, and the results are summarized in Table 4. The table showed that extracts are highly antifungal active against the three microorganisms under the concentration of $1000 \mathrm{mg} / \mathrm{L}$. As the concentration of the extracts is reduced to $500 \mathrm{mg} / \mathrm{L}$, the inhibitions are still potent for $\mathrm{AE}$, but the inhibitions of WE are depressed obviously.

\section{Conclusions}

The water and alcohol extracts of persimmon husk showed moderate to high effective inhibition in the range 10 to $1,000 \mathrm{mg} / \mathrm{L}$ in $1 \mathrm{M} \mathrm{HCl}$ at $60^{\circ} \mathrm{C}$, and the highest inhibition of $65.1 \%$ was obtained by using WE solution of 1,000 mg/L. KI, KSCN and HMTA can enhance the IE of WE effectively to $97.3 \%$ at most, but not effective for KI and KSCN to AE. Tafel polarisation measurements indicate the extracts behave as mixed type inhibitor. Investigation of the antibacterial activity against oil field microorganism showed the extracts can inhibit SRB, IB and TGB with moderate to highly efficiency under $1,000 \mathrm{mg} / \mathrm{L}$, which makes extracts potential to be used as bifunctional oil field chemicals.

\section{Competing interests}

The authors declare that they have no competing interests.

\section{Authors' contributions}

GC has conceived the study, formulated the research idea and prepared the manuscript draft version, JZ and YS carried out the corrosion inhibition experiments, HS and LZ out the Microbiological monitoring, and JZ participated in its design and coordination. All authors have read and approved the final manuscript.

\section{Acknowledgements}

Financial support from Scientific and Technological Plan Projects of Shaanxi Province (2012KJXX-40), Scientific Research Program Funded by Shaanxi Provincial Education Department (2013JK0647).

\section{Author details}

${ }^{1}$ College of Chemistry and Chemical Engineering, Xi'an Shiyou University, Xi'an Shaanxi 710065, People's Republic of China. ${ }^{2}$ Shannxi Hai'an Industry Co., LTD, Xi'an Shaanxi 710065, People's Republic of China.

Received: 23 May 2013 Accepted: 27 June 2013

Published: 1 July 2013

\section{References}

1. Borchardt JK, Yen TF: Oil-field chemistry — enhanced recovery and production stimulation. Ontario, Canada: Toronto; 1988. 608.

2. Liu YR, Gao ZM, Zhang Z, Shi DF: Electrochemically aided deposition of $\mathrm{TiO}_{2}$ films on Ni-P pre-plated A3 carbon steel. Corr Sci Prot Tech 2007, 19:323-325.

3. Jiang JH, Li L, Hu JX, Jiang JQ, Ma AB: New Zinc-phosphating process with $\mathrm{RE}$ catalyzer at low temperature for painting pretreatment of cold-rolling A3 steel sheet. Surf Tech 2007, 36(4):79-81.

4. Chen G, Zhang M, Zhao JR, Zhou R, Meng ZC, Zhang J: Investigation of Ginkgo biloba leave extracts as corrosion and oil field microorganism inhibitors. Chem Central J 2013, 7:83.

5. Gu H, Li C, Xu Y, Hu W, Chen M, Wan Q: Structural features and antioxidant activity of tannin from persimmon pulp. Food Res Int 2008, 41:208-217.

6. Mallavadhani UV, Panda AK, Rao YR: Review article number 134 pharmacology and chemotaxonomy of diospyros. Phytochemistry 1998, 49:901-915.

7. Singh AK, Quraishi MA: Investigation of adsorption of isoniazid derivatives at mild steel/hydrochloric acid interface: Electrochemical and weight loss methods. Mater Chem Phys 2012, 123:666-677.

8. Tian Y, Zou B, Li CM, Yang J, XU SF, Hagerman AE: High molecular weight persimmon tannin is a potent antioxidant both ex vivo and in vivo. Food Res Int 2012, 45:26-30.

9. Khaled KF, Hackenman N: Ortho-substituted anilines to inhibit copper corrosion in aerated $0.5 \mathrm{M}$ hydrochloric acid. Electrochim Acta 2004, 49:485-495.

10. Issaadi S, Douadi T, Zouaoui A, Chafa S, Khan MA, Bouet G: Novel thiophene symmetrical Schiff base compounds as corrosion inhibitor for mild steel in acidic media. Corros Sci 2011, 53:1484-1488.

11. Bayol E, Kayakirilmaz K, Erbil M: The inhibitive effect of hexamethylenetetramine on the acid corrosion of steel. Mater Chem Phys 2007, 104:74-79.

12. Sherbini El Foad EE: Effect of some ethoxylated fatty acids on the corrosion behaviour of mild steel in sulphuric acid solution. Mater Chem Phys 1999, 60:286-290.

13. Chen G, Su HJ, Zhang M, Huo F, Zhang J, Hao XJ, Zhao JR: New bactericide derived from isatin for treating oilfield reinjection water. Chem Central J 2012, 6:91.

14. Riedl KM, Hagerman AE: Tannin-protein complexes as radical scavengers and radical sinks. J Agric Food Chem 2001, 49:4917-4923.

doi:10.1186/1752-153X-7-109

Cite this article as: Zhang et al:: Investigation of Diospyros Kaki L.f husk extracts as corrosion inhibitors and bactericide in oil field. Chemistry Central Journal 2013 7:109. 